\title{
Effect of Pentacyclic Triterpenoids-Rich Callus Extract of Chaenomeles japonica (Thunb.) Lindl. ex Spach on Viability, Morphology, and Proliferation of Normal Human Skin Fibroblasts
}

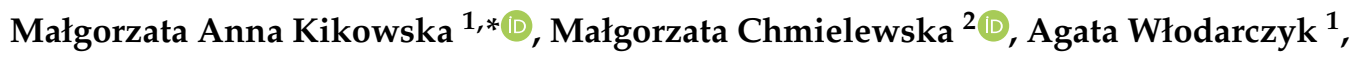 \\ Elżbieta Studzińska-Sroka ${ }^{3}$, Jerzy Żuchowski ${ }^{4}$, Anna Stochmal ${ }^{4}$, Małgorzata Kotwicka ${ }^{2}$ (D) \\ and Barbara Thiem ${ }^{1}$ \\ 1 Department of Pharmaceutical Botany and Plant Biotechnology, Poznan University of Medical Sciences, \\ 61-861 Poznań, Poland; agata_nahorska@wp.pl (A.W.); bthiem@ump.edu.pl (B.T.) \\ 2 Department of Cell Biology, Poznan University of Medical Sciences, 60-806 Poznań, Poland; \\ mchmielewska@ump.edu.pl (M.C.); mkotwic@ump.edu.pl (M.K.) \\ 3 Department of Pharmacognosy, Poznan University of Medical Sciences, 60-781 Poznań, Poland; \\ elastudzinska@ump.edu.pl \\ 4 Department of Biochemistry and Crop Quality, Institute of Soil Science and Plant Cultivation, \\ State Research Institute, 24-100 Puławy, Poland; jzuchowski@iung.pulawy.pl (J.Ż.); \\ asf@iung.pulawy.pl (A.S.) \\ * Correspondence: kikowska@ump.edu.pl; Tel.: +48-61-668-7851
}

Received: 24 September 2018; Accepted: 15 November 2018; Published: 17 November 2018

\begin{abstract}
The effect of the well-characterized callus extract of Chaenomeles japonica on viability, morphology, and proliferation of normal human skin fibroblasts was investigated. The phytochemical analysis was performed using the ultra-high performance liquid chromatography method. The total phenolic, phenolic acid, and flavonoid contents were determined spectrophotometrically. The antioxidant activity was investigated using the DPPH (1,1-Diphenyl-1-picrylhydrazyl Radical Scavenging), FRAP (Ferric Reducing Antioxidant Power), and CUPRAC (CUPric Reducing Antioxidant Capacity) assays. The callus growth index during passages was high as well as the content of pentacyclic triterpenoids. The microscopic observations of the fibroblast viability, morphology and the evaluation of the proliferation ratio (xCELLigence system) proved that the influence of callus extract on the fibroblasts was dose-dependent. The evaluated level of fibroblasts proliferation rate after $72 \mathrm{~h}$ of incubation with callus extract at concentration $12.5 \mu \mathrm{g} \mathrm{L}{ }^{-1}$ was the highest compared to all the analyzed ligands. Moreover, callus extract administrated for $72 \mathrm{~h}$ caused a significant increase in the proliferation rate in comparison with the control group ( $5.7 \pm 0.1$ vs. $4.4 \pm 0.9 ; p<0.01$ ). The preliminary studies carried out may suggest that the callus extract rich in triterpenoids may be a potential source of cosmetic ingredients with a beneficial effect on human skin.
\end{abstract}

Keywords: Chaenomeles japonica; polyphenolics; pentacyclic triterpenes; antioxidant activity; in vitro cultures; skin fibroblasts

\section{Introduction}

Chaenomeles japonica (Thunb.) Lindl. ex Spach belongs to the subfamily Maloideae of the family Rosaceae. C. japonica, a dwarf shrub that naturally occurs in Central and South Japan [1,2]. In Europe, the plant was domesticated in the 19th century and has been appreciated for its ornamental value [3]. The high content of vitamin C, organic acids, phenolic compounds, dietary fiber, pectin, simple sugars of the fruits of $C$. japonica, make them well suited for industrial processing [4-6]. 
To date, the phytochemical studies of $C$. japonica have established the presence of bioactive compounds in selected raw materials from the wild plant-epicatechin, roseoside, monoterpene glucosides and leucoanthocyanin in fruits; epicatechin and flavonol glycosides in leaves; and daucosterol, three triterpenes-ursolic, oleanolic, pomolic acids, and epicatechin, prunasin in roots [7]. Among all representatives of the genus Chaenomeles, in the traditional medicine of the Far East, the fruits of Chaenomeles speciosa were used for centuries as 'Mugua', while the fruits of $C$. japonica have been used as an astringent and in stomach diseases [8]. Moreover, the extract from seeds of $C$. japonica is on the list of cosmetic ingredients approved for use in the European Union, acting as a supplement that nourishes the skin [9].

There is a growing interest in pentacyclic triterpenoids due to their interesting potential biological and pharmaceutical properties. Oleanolic acid and its isomer-ursolic acid-have long been known to be anti-inflammatory, hepato-protective, and anti-hyperlipidemic in the traditional medicine of Asia. Moreover, recently there have been many studies on the antiviral, antimicrobial and anticancer activities [10], and the anti-aging effect [11]. Betulinic acid was reported for its cosmetic properties [12]. The production of pentacyclic triterpenoids in vitro cultures (callus and cell suspension cultures) of various plants has been investigated. Several studies showed the production of oleanolic, ursolic and betulic acids by plants in vitro cultures [13].

Polyphenols are a group of common bioactive secondary metabolites widely distributed in plants. They exhibit a great diversity and are divided into several classes. The phenolic constituents have a wide range of biological activities, mainly attributed to their antioxidant potential [14]. Polyphenols possess a broad spectrum of activities applied in cosmetology-skin cell renewal, stimulation of collagen and elastin synthesis or elimination of oxidative stress. For these reasons, they have been perceived as effective anti-aging agents [15].

Therefore, callus and cell suspension cultures are widely applied in the investigation of the production of the high-value secondary metabolites, which may be used as cosmeceuticals, nutraceuticals, and pharmaceuticals. Plant cell cultures, with the continuous and reliable accumulation of desired bioactive compounds, are promising; an alternative to intact plants, sources for the production of the plant-derived drugs of industrial importance. In comparison with the conventional cultivation of plants, plant cell cultures offer an independent-of geographical and environmental factors-supply of uniform biomass with enhanced production of active constituents. Plant in vitro cultures ensure a rational utilization of biodiversity [16,17].

Fibroblasts, which were the object of this research, are the most common cells of connective tissue. The number of fibroblasts in the human dermis decreases with age and it is partially due to the reduced proliferation [18]. The research for finding natural substances with beneficial effects on the biological activities of skin fibroblasts is still needed.

The aim of this study was to investigate the effect of the well-characterized and rich in pentacyclic triterpenoids callus extract (line A2) of Chaenomeles japonica on the viability, morphology, and proliferation of normal human skin fibroblasts. For this reason, the authors initiated, established, and selected callus lines determined the main compounds in four lines of callus and evaluated the antioxidant activity of the extracts. The callus line A2 was chosen for the fibroblast-based experiments.

\section{Results}

The in vitro cultures of $C$. japonica were initiated from the seeds of intact plants (according to Reference [19]). The leaves from the shoot cultures (the stage of micro-propagation) were employed for the establishment of the callus. The induction of the callus occurred on all explants submitted to different plant growth regulators (100\% efficiency). The callus biomass was friable and varied in color (Figure 1). 


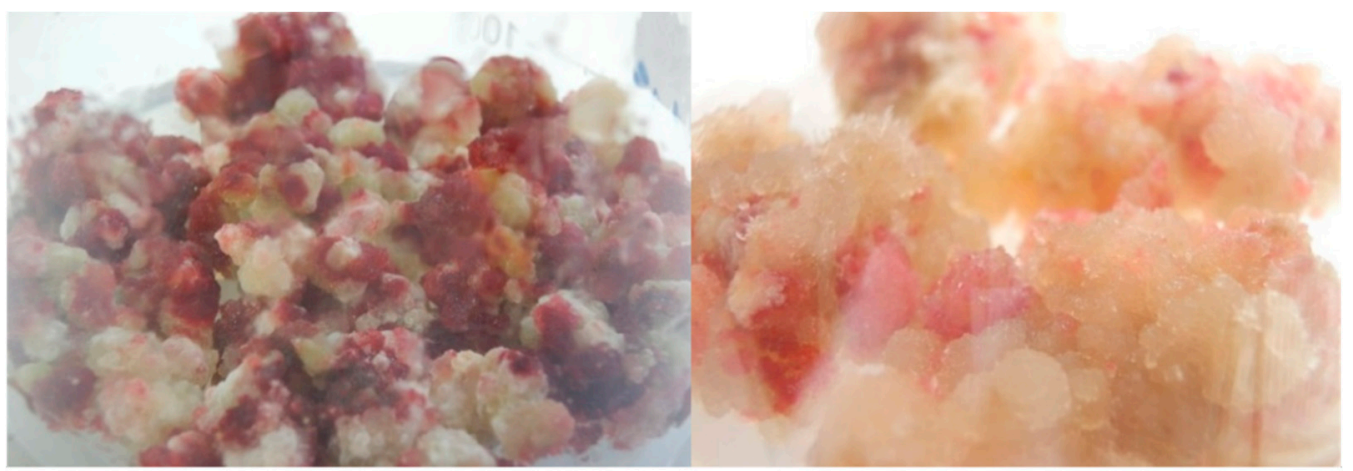

(a)

(b)

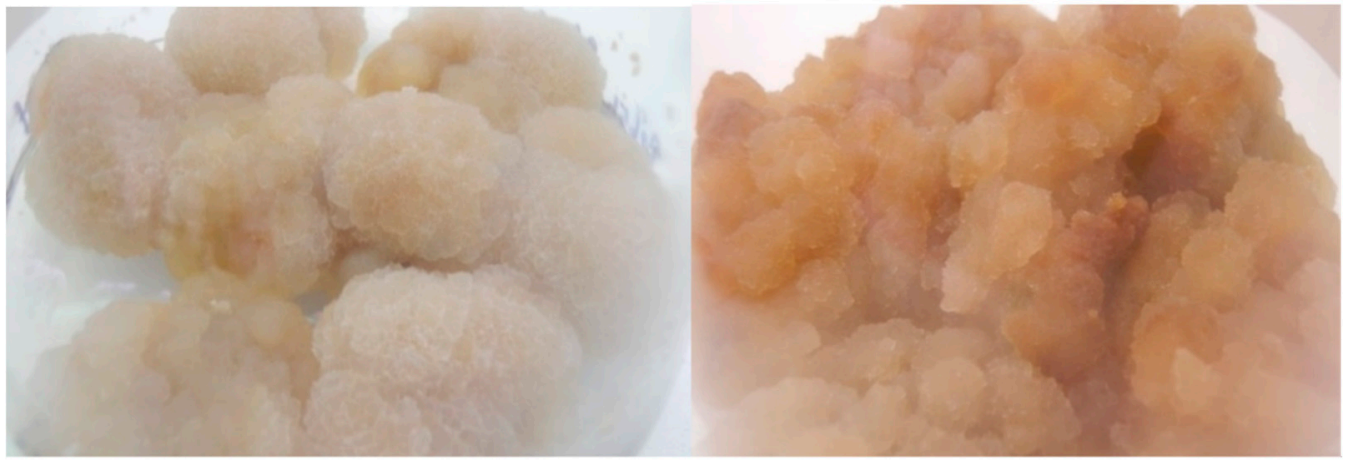

(c)

(d)

Figure 1. The callus lines of Chaenomeles japonica cultured in vitro on MS (Murashige and Skoog) media (a) Line A1: MS + $1.0 \mathrm{mg} \mathrm{L}^{-1} 2,4 \mathrm{D}+0.1 \mathrm{mg} \mathrm{L}^{-1} \mathrm{Kin}$ (light); (b) Line A2: MS + $1.0 \mathrm{mg} \mathrm{L}^{-1} 2,4 \mathrm{D}+0.1 \mathrm{mg}$ $\mathrm{L}^{-1}$ Kin (dark); (c) Line B: MS + $2.0 \mathrm{mg} \mathrm{L}^{-1} 2,4 \mathrm{D}+0.2 \mathrm{mg} \mathrm{L}^{-1} \mathrm{NAA}$ (d) Line C: MS + $1.0 \mathrm{mg} \mathrm{L} \mathrm{gIC}^{-1}$.

For subsequent experiments the leaf-derived callus was maintained on the three selected MS (Murashige and Skoog) media enriched with the phytohormones: MS $+1.0 \mathrm{mg} \mathrm{L}^{-1} 2,4 \mathrm{D}$ (2,4-dichlorophenoxyacetic acid) $+0.1 \mathrm{mg} \mathrm{L}^{-1} \mathrm{KIN}$ (kinetin/ 6-furfurylaminoaminopurine) (kept in the light: A1 line, in the dark: A2 line), MS + $2.0 \mathrm{mg} \mathrm{L}^{-1} 2,4 \mathrm{D}+0.2 \mathrm{mg} \mathrm{L}^{-1} \mathrm{NAA}$ ( $\alpha$-naphthaleneacetic acid) (kept in the dark: B line), and MS + $1.0 \mathrm{mg} \mathrm{L}^{-1} \mathrm{DIC}$ (dicamba/ 3,6-dichloro-2-methoxybenzoic acid) (kept in the dark: $\mathrm{C}$ line).

On these selected growing media, the biomass of the studied lines of callus intensively increased, reaching high rates of cell proliferation during the latest passages. The callus growth index depended on the line tested and ranged from $844.98 \pm 28.62 \%$ to $893.90 \pm 21.68 \%$ (Table 1, Figure 1).

Table 1. The growth parameters of selected lines of Chaenomeles japonica callus growing on various variants of MS (Murashige and Skoog) medium.

\begin{tabular}{ccccc}
\hline \multirow{2}{*}{ Callus Line } & \multicolumn{4}{c}{ Callus Growth Index (\%) \pm Standard Error } \\
\cline { 2 - 5 } & Passage 23 & Passage 24 & Passage 25 & Mean \\
\hline A1 & $859.93 \pm 13.82$ & $842.10 \pm 29.31$ & $970.23 \pm 37.66$ & $893.90^{\mathrm{ns}} \pm 21.68$ \\
$\mathrm{~A} 2$ & $863.81 \pm 44.37$ & $841.22 \pm 65.35$ & $849.62 \pm 35.53$ & $849.62 \pm 35.53$ \\
B & $689.00 \pm 55.30$ & $915.40 \pm 49.58$ & $863.02 \pm 38.56$ & $863.02 \pm 38.56$ \\
C & $849.46 \pm 47.22$ & $841.63 \pm 31.74$ & $844.98 \pm 28.62$ & $844.98 \pm 28.62$ \\
\hline \multicolumn{5}{c}{ Ns: no significant differences at $\mathrm{P}=0.05$ (Duncan's test). }
\end{tabular}

Although the A2 line callus was characterized by the lowest concentration of polyphenols, mainly phenolic acids (the sum of chlorogenic acid, dicaffeoylquinic acid, hexoside quercetin and epicatechin was $0.21 \mathrm{mg} \mathrm{g}^{-1} d . w$. , the total content of phenolic acids was $1.67 \pm 0.03 \mathrm{mg} \mathrm{CA} \mathrm{g}^{-1}$ ) and a negligible level of flavonoids (the total content of flavonoids was $0.47 \pm 0.01 \mathrm{mg} \mathrm{QE} \mathrm{g}^{-1}$ ), and thus the lowest antioxidant activity (the CUPric Reducing Antioxidant Capacity assay-CUPRAC: 
$\mathrm{IC}_{0.5} 187.70 \mu \mathrm{g} \mathrm{mL}{ }^{-1}$, the Ferric Reducing Antioxidant Power assay-FRAP: $\mathrm{IC}_{0.5} 168.08 \mu \mathrm{g} \mathrm{mL}{ }^{-1}$, the1,1-diphenyl-1-picrylhydrazyl Radical Scavenging assay-DPPH: $\mathrm{IC}_{50} 516.88 \mu \mathrm{g} \mathrm{mL}^{-1}$ ). It, however, had the highest content of pentacyclic triterpenoids (the sum of ursolic acid, oleanolic acid and betulinic acid $-9.81 \pm 0.89 \mathrm{mg} \mathrm{g}^{-1}$ d.w.) (Tables 2-5; Figure 2) and on this basis, was selected for further research of biological activities on fibroblasts.

Table 2. The content ( $\mathrm{mg} \mathrm{g}^{-1}$ d.w.) of selected polyphenols in four lines of Chaenomeles japonica callus.

\begin{tabular}{cccccc}
\hline \multirow{2}{*}{ Callus Line/Plant Material } & \multicolumn{5}{c}{ Polyphenols [Content $\mathbf{~ m g ~ g ~}^{\mathbf{- 1}} \pm$ Standard Error] } \\
\cline { 2 - 5 } & CA & DCCA & HQ & EC & Sum of CA, DCCA, HQ, EC \\
\hline A1 & $1.09 \pm 0.08$ & $0.08 \pm 0.01$ & $0.06 \pm 0.01$ & $0.07 \pm 0.01$ & $1.30 \pm 0.10$ \\
A2 & $0.12 \pm 0.01$ & $0.05 \pm 0.01$ & $0.05 \pm 0.00$ & trace & $0.21 \pm 0.02$ \\
B & $2.68 \pm 0.15$ & - & $0.06 \pm 0.01$ & $0.08 \pm 0.02$ & $2.81 \pm 0.16$ \\
C & $0.93 \pm 0.04$ & $0.25 \pm 0.01$ & $0.10 \pm 0.00$ & $0.09 \pm 0.01$ & $1.36 \pm 0.05$ \\
Fruit & $0.96 \pm 0.05$ & - & - & $0.30 \pm 0.06$ & $1.25 \pm 0.09$ \\
\hline
\end{tabular}

CA: chlorogenic acid, DCCA: dicaffeoylquinic acid, HQ: hexoside quercetin, EC: epicatechin.

Table 3. The content $\left(\mathrm{mg} \mathrm{g}^{-1} d . w\right.$.) of selected pentacyclic triterpenes in four lines of Chaenomeles japonica callus.

\begin{tabular}{ccccc}
\hline \multirow{2}{*}{ Callus Line/Plant Material } & \multicolumn{4}{c}{ Pentacyclic Triterpenes } \\
\cline { 2 - 5 } & UA & OA & BA & Sum of UA, OA, BA \\
\hline A1 & $4.27 \pm 0.65$ & $3.92 \pm 0.37$ & $0.43 \pm 0.03$ & $8.62 \pm 1.15$ \\
A2 & $5.00 \pm 0.61$ & $4.35 \pm 0.30$ & $0.46 \pm 0.03$ & $9.81 \pm 0.89$ \\
B & $1.22 \pm 0.09$ & $1.26 \pm 0.09$ & $0.22 \pm 0.01$ & $2.70 \pm 0.17$ \\
C & $2.27 \pm 0.19$ & $1.48 \pm 0.11$ & $0.25 \pm 0.02$ & $4.00 \pm 0.29$ \\
Fruit & $1.85 \pm 0.19$ & $1.51 \pm 0.17$ & $0.58 \pm 0.05$ & $3.94 \pm 0.43$ \\
\hline
\end{tabular}

UA: ursolic acid, OA: oleanolic acid, BA: betulinic acid.

Table 4. The total content of total polyphenolics, phenolic acids, and flavonoids in four lines of Chaenomeles japonica callus.

\begin{tabular}{|c|c|c|c|c|c|}
\hline \multirow{2}{*}{ Total } & \multicolumn{5}{|c|}{ Content of Selected Groups of Compounds in Extracts [ \pm Standard Error] } \\
\hline & A1 & A2 & B & $\mathrm{C}$ & Fruit \\
\hline POLYPHENOLS [mg GAE g ${ }^{-1}$ ] & $20.60 \pm 0.20$ & $8.87 \pm 0.21$ & $41.05 \pm 0.84$ & $6.61 \pm 0.57$ & $52.50 \pm 1.58$ \\
\hline PHENOLIC ACIDS [mg CAE $\mathrm{g}^{-1}$ ] & $22.48 \pm 0.82$ & $1.67 \pm 0.03$ & $7.11 \pm 0.15$ & $4.80 \pm 0.07$ & $18.02 \pm 0.36$ \\
\hline FLAVONOIDS [mg QE g ${ }^{-1}$ ] & $0.60 \pm 0.07$ & $0.47 \pm 0.01$ & $0.986 \pm 0.03$ & $0.64 \pm 0.02$ & $0.33 \pm 0.01$ \\
\hline
\end{tabular}

GAE: gallic acid equivalent, $C A E$ : caffeic acid equivalent, $Q E$ : quercetin equivalent.

Table 5. The antioxidant effect of four lines of Chaenomeles japonica callus.

\begin{tabular}{|c|c|c|c|}
\hline Plant Material & $\begin{array}{c}\text { CUPRAC } \\
\mathrm{IC}_{0.5}\left(\mu \mathrm{g} \mathrm{mL}^{-1}\right)\end{array}$ & $\begin{array}{c}\text { FRAP } \\
\mathrm{IC}_{0.5}\left(\mu \mathrm{g} \mathrm{mL}^{-1}\right)\end{array}$ & $\begin{array}{c}\mathrm{DPPH} \\
\mathrm{IC}_{50}\left(\mu \mathrm{g} \mathrm{mL}^{-1}\right)\end{array}$ \\
\hline A1 & 90.05 & 62.69 & 178.51 \\
\hline $\mathrm{A} 2$ & 187.70 & 168.08 & 516.88 \\
\hline B & 117.18 & 92.72 & 305.49 \\
\hline C & 110.03 & 75.14 & 234.00 \\
\hline Fruit & 40.91 & 27.62 & 75.11 \\
\hline Vitamin C & 9.28 & 5.03 & 5.48 \\
\hline
\end{tabular}




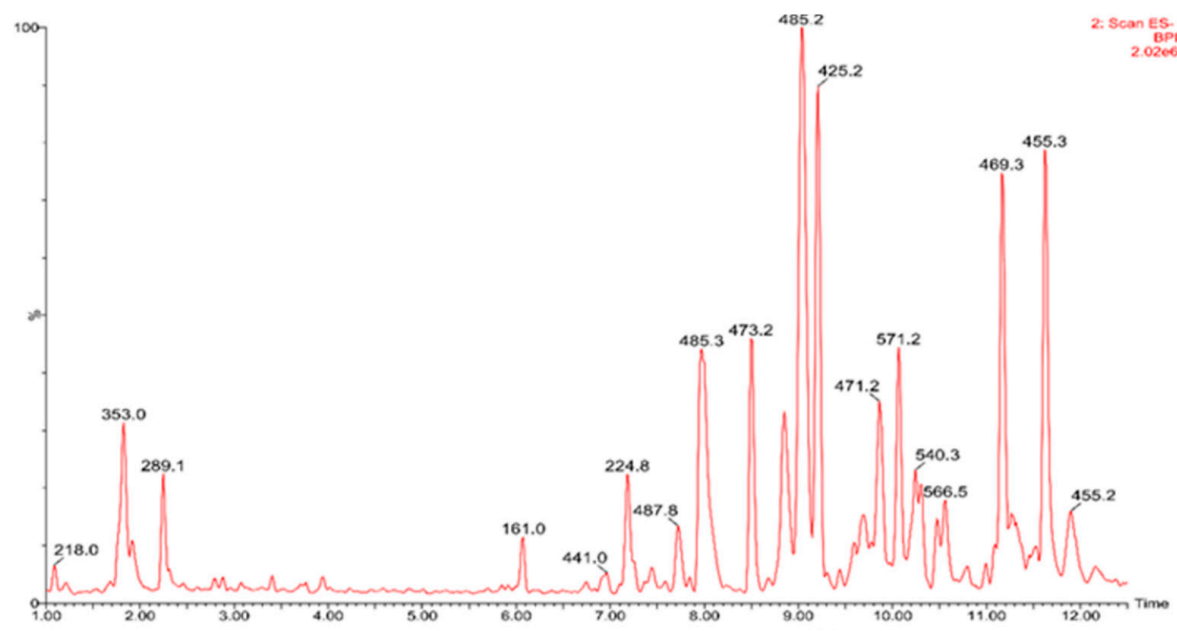

(a)

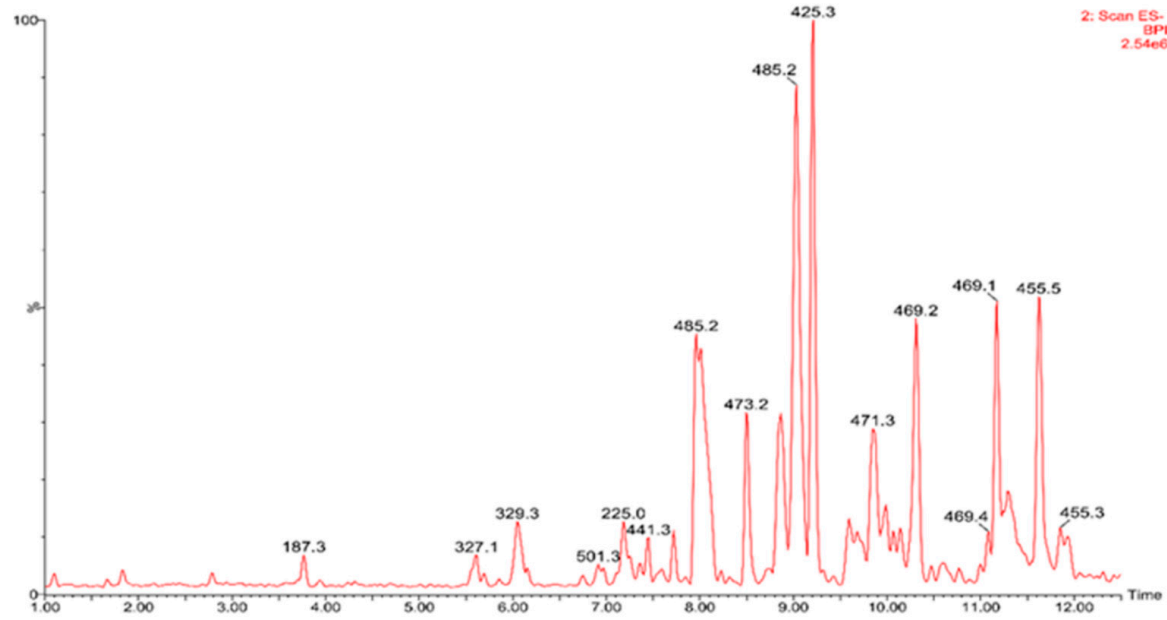

(b)
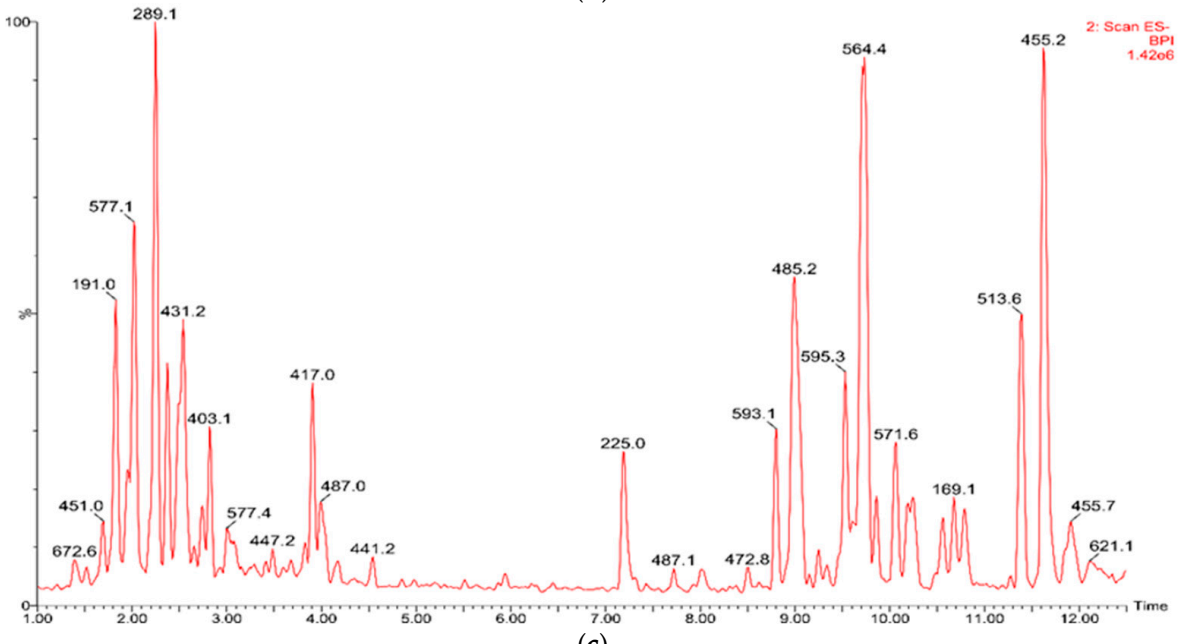

(c)

Figure 2. The High Performance Liquid Chromatography Tandem Mass Spectrometry (HPLC-MS/MS) chromatograms of extracts from Chaenomeles japonica (a) callus A1 (b) callus A2 (c) fruits.

Figure 3 shows the morphology of the control fibroblasts and those treated with C. japonica extract from the callus A2 line in the selected concentrations and time intervals. 


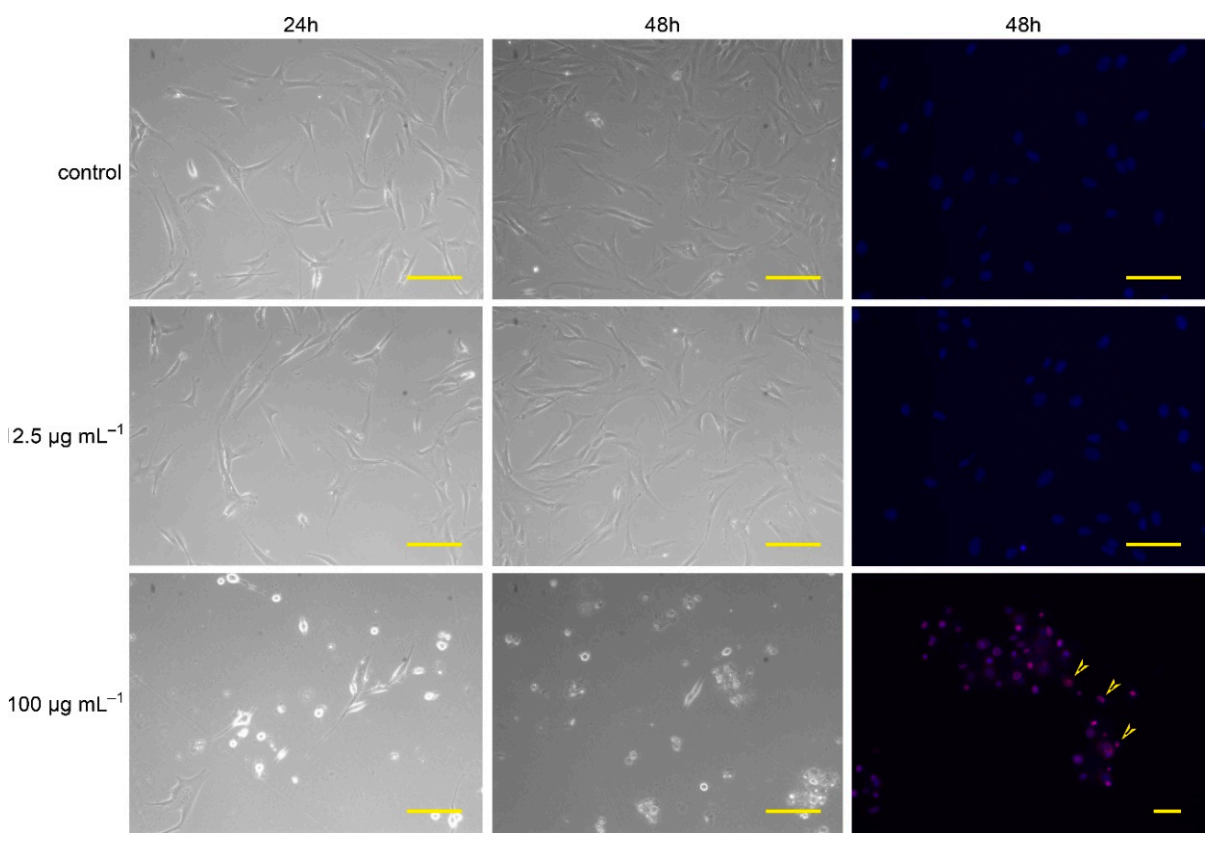

Figure 3. The human skin fibroblast cell morphology. The left column and the middle column show untreated control cells and cells stimulated with C. japonica callus extract at a final concentration of 12.5 and $100 \mu \mathrm{g} \mathrm{mL}{ }^{-1}$ after 24 and $48 \mathrm{~h}$ of incubation, respectively. The right column shows cells stained with propidium iodide/Hoechst33342 after $48 \mathrm{~h}$ of incubation with $C$. japonica callus extract at a final concentration of 12.5 and $100 \mu \mathrm{g} \mathrm{mL}^{-1}$; yellow scale bar $=50 \mu \mathrm{m}$; yellow arrows indicate the dead cells stained with propidium iodide.

It can be seen that non-stimulated cells and fibroblasts treated with a callus extract at a lower concentration $\left(12.5 \mu \mathrm{g} \mathrm{mL}{ }^{-1}\right)$ were characterized by a correct, elongated shape. The cells contained centrally located large and round nuclei that revealed chromatin with a granular structure. The morphology of the fibroblasts treated with $100 \mu \mathrm{g} \mathrm{mL}-1$ extract was characterized by an incorrect morphology with narrow projections. Many dead cells were observed among these fibroblasts.

As a result of the microscopic observations of the fibroblast morphology (Figure 3 ) and the evaluation of the proliferation ratio (Figure 4), it can be noticed that the influence of $C$. japonica callus extract on the fibroblasts was dose-dependent.

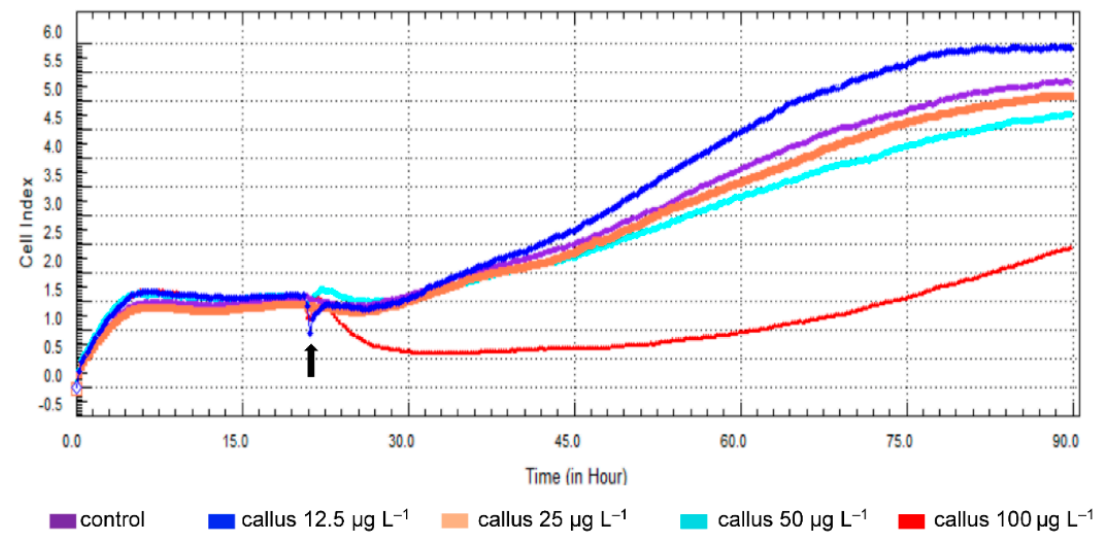

Figure 4. The real-time, label-free monitoring of the callus extracts effects of on CRTL-2522 human skin fibroblast proliferation using the xCELLigance system. A representative graph is shown. CRTL-2522 cells were treated with various concentrations of callus extract. The cell index value was monitored in real-time for $72 \mathrm{~h}$ (black arrow indicates the time of callus extract administration). 
Cell proliferation assays were performed using the xCELLigence system (ACEA Biosciences Inc., San Diego, CA, USA). After seeding CRL-2522 cells into the wells, the mean impedance change $(n=5)$ was measured. No significant differences in the proliferation rate among all analyzed groups were observed before stimulation $(p>0.05)$. Impedance was monitored every $15 \mathrm{~min}$. Only four post stimulation points were analyzed: at $12,24,48$, and $72 \mathrm{~h}$ to improve the clarity of the results presentation. The control cells showed a significant cell index increase, which, $12 \mathrm{~h}$ after stimulation, attained $1.4 \pm 0.4$ and increased to $4.4 \pm 1.2$ after $72 \mathrm{~h}$ of incubation $(p<0.001)$.

RTCA DP software (Version 1.2.1, ACEA Biosciences Inc., San Diego, CA, USA) analysis performed after 12, 24, 48, or $72 \mathrm{~h}$ incubation showed a significant decrease of the cell index (CI) in case of cells stimulated with callus extract at final concentrations 100 or $50 \mu \mathrm{g} \mathrm{L}^{-1}$ in comparison to control. However, the rate of CI in CRL-2522 cells stimulated with callus extract of $12.5 \mu \mathrm{g} \mathrm{L}^{-1}$ was higher in comparison to the control cells in all time intervals (Table 6).

Table 6. The effect of callus extracts of Chaenomeles japonica, kinetin, and fruit extracts on the proliferation rate of CRL-2522 cells.

\begin{tabular}{|c|c|c|c|c|}
\hline \multirow{3}{*}{ Plant Material/Reference Compound } & \multicolumn{4}{|c|}{ Cell Index Value Mean \pm Standard Deviation } \\
\hline & \multicolumn{4}{|c|}{ Incubation Time } \\
\hline & $12 \mathrm{~h}$ & $24 \mathrm{~h}$ & $48 \mathrm{~h}$ & $72 \mathrm{~h}$ \\
\hline $\begin{array}{l}\text { Control } \\
\text { Callus }\end{array}$ & $1.4 \pm 0.4$ & $1.9 \pm 0.5$ & $3.3 \pm 0.5$ & $4.4 \pm 0.6$ \\
\hline$\left(100 \mu \mathrm{g} \mathrm{L}^{-1}\right)$ & $0.2 \pm 0.0^{* *}$ & $0.2 \pm 0.0^{* *}$ & $0.2 \pm 0.0 * *$ & $0.1 \pm 0.1 * *$ \\
\hline$\left(50 \mu \mathrm{g} \mathrm{L}^{-1}\right)$ & $0.5 \pm 0.1 * *$ & $0.5 \pm 0.1 * *$ & $0.8 \pm 0.4^{* *}$ & $1.3 \pm 0.9^{* *}$ \\
\hline$\left(25 \mu \mathrm{g} \mathrm{L}^{-1}\right)$ & $1.4 \pm 0.4$ & $1.6 \pm 0.6$ & $2.9 \pm 0.7$ & $4.2 \pm 0.4$ \\
\hline $\begin{array}{c}\left(12.5 \mu \mathrm{g} \mathrm{L}^{-1}\right) \\
\text { Kinetin }\end{array}$ & $1.7 \pm 0.4$ & $2.1 \pm 0.5$ & $3.8 \pm 0.6$ & $5.7 \pm 0.1$ * \\
\hline$\left(100 \mu \mathrm{g} \mathrm{L}^{-1}\right)$ & $1.4 \pm 0.0$ & $1.4 \pm 0.0$ & $1.7 \pm 0.1$ & $1.5 \pm 0.3$ \\
\hline$\left(50 \mu \mathrm{g} \mathrm{L}^{-1}\right)$ & $1.3 \pm 0.3$ & $1.6 \pm 0.6$ & $2.4 \pm 1.0$ & $3.1 \pm 1.5$ \\
\hline$\left(25 \mu \mathrm{g} \mathrm{L}^{-1}\right)$ & $1.2 \pm 0.6$ & $1.3 \pm 0.6$ & $2.3 \pm 1.1$ & $3.5 \pm 1.5$ \\
\hline$\left(12.5 \mu \mathrm{g} \mathrm{L}^{-1}\right)$ & $1.4 \pm 0.6$ & $1.5 \pm 0.6$ & $2.9 \pm 1.2$ & $4.3 \pm 1.5$ \\
\hline Fruit & & & & \\
\hline$\left(100 \mu \mathrm{g} \mathrm{L}^{-1}\right)$ & $0.5 \pm 0.1^{* *}$ & $0.5 \pm 0.1^{* *}$ & $0.8 \pm 0.5^{* *}$ & $0.8 \pm 0.6^{* *}$ \\
\hline$\left(50 \mu \mathrm{g} \mathrm{L}^{-1}\right)$ & $1.2 \pm 0.8$ & $1.3 \pm 0.8$ & $2.1 \pm 1.3$ & $2.6 \pm 1.7$ \\
\hline$\left(25 \mu \mathrm{g} \mathrm{L}^{-1}\right)$ & $1.4 \pm 0.5$ & $1.5 \pm 0.5$ & $2.8 \pm 0.5$ & $4.3 \pm 0.5$ \\
\hline$\left(12.5 \mu \mathrm{g} \mathrm{L}^{-1}\right)$ & $1.4 \pm 0.6$ & $1.6 \pm 0.7$ & $2.9 \pm 1.0$ & $4.3 \pm 1.0$ \\
\hline$P$-value & $<0.0001$ & $<0.0001$ & $<0.0001$ & $<0.0001$ \\
\hline
\end{tabular}

Cell index value was monitored using the xCELLigance system. Results are from five repeats. $P$-value calculated from one-way analysis of the variance; ${ }^{*} p<0.01$ vs. control; ${ }^{* *} p<0.001$ vs. control.

The representative graph, comparing the rate of CI in callus extracts stimulated CRL-2522 cells, was presented in Figure 4. The evaluated level of the fibroblast proliferation rate after $72 \mathrm{~h}$ of incubation with $12.5 \mu \mathrm{g} \mathrm{L}{ }^{-1}$ callus extract was the highest compared to all analyzed ligands. Moreover, the callus extract administrated for $72 \mathrm{~h}$ caused a significant increase in the proliferation rate in comparison with the control group ( $5.7 \pm 0.1$ vs. $4.4 \pm 0.9 ; p<0.01)$.

Kinetin (N6-furfuryladenine), known from the literature as a small-molecule plant compound that acts as a growth factor, has been selected as a reference substance. It is one of the cytokinin compounds, where anti-aging effects on cultured human skin cells have been reported [20,21]. However, in our study after kinetin stimulation, no difference between the proliferation rate of CRL-2522 fibroblasts and the control cells was observed.

\section{Discussion}

The beneficial effect of the $C$. japonica callus extract on fibroblasts may be related to the compounds present in the biomass, in which pentacyclic triterpenoids and phenolic compounds predominate. 
The preliminary studies carried out may suggest that the callus extract rich in triterpenoids may be a potential source of cosmetic ingredients with a beneficial effect on human skin.

As it is known from the literature, ursolic and oleanolic acids (those compounds present in extracts from the callus and fruits of $C$. japonica), have demonstrated activity on human fibroblasts [22]. Oleanolic acid with less cytotoxicity than ursolic acid can be used as a complementary ingredient in products intended for dermal use [22]. However, the liposome-encapsulated ursolic acid increased the collagen synthesis of dermal fibroblasts and it is a promising agent with a wide variety of applications, for example, in anti-aging skin care products [23]. Moreover, the extract of Manilkara bidentate, with a beneficial effect on collagen and fibronectin synthesis and the extract of birch (Betula sp.) bark, both rich in pentacyclic triterpenes, have been considered as anti-aging ingredients for the cosmetic industry [24,25]. Asiaticoside, an active compound belonging to pentacyclic terpenoids from Centella asiatica, has enhanced the number of normal human dermal fibroblasts in the in vitro system [26]. The Terminalia chebula fruit extract is rich in phenolic acids and flavonol glycosides. Fibroblasts treated with extracts of this species at concentrations of $10-100 \mu \mathrm{g} \mathrm{mL}^{-1}$ survived and were divided even up to day 21 of culture. The cytoprotective effect of the extracts of this plant has been demonstrated in combination with high antioxidant activity. Treated fibroblasts were characterized by a normal morphology and good parameters of growth [27]. The extract from Symphytum officinale rich in phenolic acids (including hydroxybenzoic acid, chlorogenic acid, and p-coumaric acid) characterized by the lack of cytotoxicity, stimulates the viability and metabolism of human skin fibroblast cells [28]. Furthermore, the extract of Persea americana seeds, mostly composed of quinic acid, chlorogenic acid, and their isomers, enhanced the proliferation rate of human skin fibroblasts and keratinocytes and did not affect their cytotoxicity [29]. The extracts from C. japonica are rich in chlorogenic acid, which is known from the literature as a compound affecting, among others, the proliferation of fibroblasts and preferably, acting to improve skin regeneration [30].

The authors believe that the $C$. japonica extracts are worthy to be investigated in regard to their properties to positively affect the skin, which is related to the presence of valuable compounds. Many researchers suggest that extracts rich in bioactive compounds, as opposed to single compounds, can be characterized by synergistic effects on cells, increasing their proliferation rate and scavenging free radicals [27]. A breakthrough in understanding human skin cells (e.g., fibroblasts, keratinocytes) treated with plant-derived extracts with well-defined and natural ingredients offers a pathway for anti-aging product development. Our research brings us closer to understanding how the C. japonica callus extract may influence the cultured fibroblasts, cells of connective tissue, which number decreases during the aging process of the skin.

\section{Materials and Methods}

\subsection{Plant Material, Surface Disinfection, and Culture Media Establishment}

The voucher specimens of $C$. japonica (no. 1526/2016) are deposited in the Herbarium of the Medicinal Plant Garden in the Institute of Natural Fibers and Medicinal Plants in Poznan, Poland. The mature fruits of $C$. japonica were collected from the old shrub growing in the garden $\left(52^{\circ} 21^{\prime} 55.4^{\prime \prime}\right.$ N 17 $00^{\prime} 12.5^{\prime \prime}$ E; 52.365381, 17.003471) in Poznan (Poland), in 2013. For the aseptic culture initiation, the seeds were isolated from fresh fruits, surface disinfected, and used as primary explants. The isolated seeds were washed in distilled water for $5 \mathrm{~min}$ followed by submerging in $70 \%(v / v)$ ethanol for $30 \mathrm{~s}$ to degrease the seeds and placed on lignin in a thermostat $\left(26^{\circ} \mathrm{C}\right)$ for $24 \mathrm{~h}$ to swell the seeds. After this pretreatment, the seeds were disinfected with commercial bleach at a $50 \%$ concentration for $20 \mathrm{~min}$ with two drops of Tween 20. They were finally rinsed 5 times in sterilized bi-distilled water and transferred to Murashige and Skoog (MS) [31] medium to obtain the aseptic seedlings, whose parts were the secondary explants for in vitro cultures establishment. All types of culture media consisted of MS basal media solidified with $0.8 \%(w / v)$ agar (Sigma-Aldrich, Saint. Louis, MO, USA) supplemented with $30 \mathrm{~g} \mathrm{~L}^{-1}(w / v)$ sucrose and plant growth regulators at various concentrations. All plant growth 
regulators originated from Sigma-Aldrich (St. Louis, Saint Louis, MO, USA). After adjusting $\mathrm{pH}$ to 5.8 , the media were autoclaved at $121^{\circ} \mathrm{C}$ for $20 \mathrm{~min}$ at $105 \mathrm{kPa}$. Cultures were incubated in a growth chamber (16/8 $\mathrm{h}$ photoperiod, $55 \mu \mathrm{mol} \mathrm{m}{ }^{-2} \mathrm{~s}^{-1}$ light, temp. $\left.21 \pm 2{ }^{\circ} \mathrm{C}\right)$.

\subsection{Induction and Maintenance of Callus}

The callus culture was initiated from the leaves of the micropropagated plantlet explants on various solid MS media (1.0 mg L $\mathrm{m}^{-1}$ 2,4-D + $0.1 \mathrm{mg} \mathrm{L}^{-1} \mathrm{KIN}, 1.0 \mathrm{mg} \mathrm{L}^{-1}$ 2,4-D + $1.0 \mathrm{mg} \mathrm{L}^{-1} \mathrm{KIN}, 2.0 \mathrm{mg} \mathrm{L}^{-1}$ 2,4-D + $1.0 \mathrm{mg} \mathrm{L}^{-1} \mathrm{KIN}, 0.5 \mathrm{mg} \mathrm{L}^{-1}$ 2,4-D + $0.05 \mathrm{mg} \mathrm{L}^{-1} \mathrm{NAA}, 1.0 \mathrm{mg} \mathrm{L}^{-1} 2,4-\mathrm{D}+0.1 \mathrm{mg} \mathrm{L}^{-1} \mathrm{NAA}_{\text {, }}$

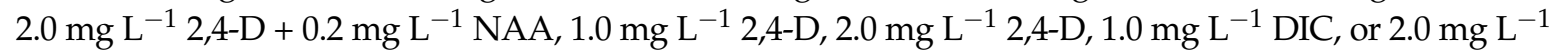
$\mathrm{DIC}$ ) and then established on selected MS with $1.0 \mathrm{mg} \mathrm{L}^{-1} 2,4 \mathrm{D}+0.1 \mathrm{mg} \mathrm{L}^{-1} \mathrm{KIN}$ (light condition) (line A1), MS with $1.0 \mathrm{mg} \mathrm{L}^{-1} 2,4 \mathrm{D}+0.1 \mathrm{mg} \mathrm{L}^{-1} \mathrm{KIN}$ (dark condition) (line A2), MS with $2.0 \mathrm{mg} \mathrm{L}^{-1} 2,4 \mathrm{D}+$ $0.2 \mathrm{mg} \mathrm{L}^{-1} \mathrm{NAA}$ (dark condition) (line B), $\mathrm{MS}+1.0 \mathrm{mg} \mathrm{L}^{-1} \mathrm{DIC}$ (dark condition) (line C). Sub-cultures were performed at 4-week intervals. Callus initiation and its development were first observed visually and then when callus culture became stabilized (23-25 passages), the growth callus index was calculated by the following equation: Growth index = (final dry cell weight - initial dry cell weight)/initial dry cell weight.

The stable and homogenous leaf-derived callus (line A2) growing in the darkness, on a medium MS with $1.0 \mathrm{mg} \mathrm{L}^{-1} 2,4 \mathrm{D}+0.1 \mathrm{mg} \mathrm{L}^{-1} \mathrm{KIN}\left(26^{\text {th }}\right.$ subculture), after phytochemical analyses were chosen for the biological experiments.

\subsection{Phytochemical Analysis}

Lyophilized plant samples (100 mg) were ground in a mortar and extracted with $80 \%(v / v)$ methanol, using the accelerated solvent extraction system (ASE 200, Dionex, Sunnyvale, CA, USA). Extraction was carried out at $100{ }^{\circ} \mathrm{C}$, operating pressure was 1500 psi. The extracts were evaporated to dryness, suspended in 5\% MeOH, and subjected to solid phase extraction (SPE) on Waters SepPak Classic cartridges equilibrated with 5\% MeOH. The analytes were eluted with $95 \% \mathrm{MeOH}$, evaporated to dryness and reconstituted in $3.000 \mathrm{~mL}$ of $90 \% \mathrm{MeOH}$. The samples were then stored in $-20{ }^{\circ} \mathrm{C}$ and centrifuged at 23,000 x g for $15 \mathrm{~min}$ before analysis. UHPLC-DAD-ESI-MS analyzes were performed using an ACQUITY UPLC ${ }^{\circledR}$ chromatographic system (Waters Corp., Milford, MA, USA), equipped with a triple quadrupole mass detector.

For the determination of the content of oleanolic, ursolic, and betulinic acids, an ACQUITY HSS C18 column $(2.1 \times 100 \mathrm{~mm}, 100 \AA, 1.8 \mu \mathrm{m}$; Waters, Milford, MA, USA) was used, the flow rate was $0.400 \mathrm{~mL}$ $\min ^{-1}\left(30^{\circ} \mathrm{C}\right)$, and the injection volume was $2.5 \mu \mathrm{L}$. Analytes were separated isocratically for $11.9 \mathrm{~min}$ using $80 \%$ methanol containing $0.1 \%$ formic acid. The column was subsequently washed with $99 \% \mathrm{MeOH}$ ( $0.1 \%$ formic acid) (12-13 $\mathrm{min}$ ) and the initial conditions were restored (13.1-15.0 min). Triterpenoid acids were detected by MS in the negative ionization mode, using the Selected Ion Monitoring (SIM) method. The following MS settings were applied: capillary voltage was $2.8 \mathrm{kV}$; cone voltage was $80 \mathrm{~V}$; source temperature was $140{ }^{\circ} \mathrm{C}$, desolvation temperature was $350{ }^{\circ} \mathrm{C}$, cone gas flow (nitrogen) was $100 \mathrm{~L} \mathrm{~h}^{-1}$, desolvation gas flow was $800 \mathrm{~L} \mathrm{~h}^{-1}$. The content of ursolic and oleanolic acid in the investigated samples was determined by external calibration (oleanolic acid: $y=-456,02 \times 2+52103 x+70463, \mathrm{R} 2=0,991$; ursolic acid: $y=-339,1 \times 2+40079 x+67659, R 2=0,990)$. The betulinic acid content was expressed as oleanolic acid equivalent. Phenolic compounds were determined using an ACQUITY BEH C18 column $(2.1 \times 100 \mathrm{~mm}$, $130 \AA, 1.7 \mu \mathrm{m}$; Waters), maintained at $50^{\circ} \mathrm{C}$. The injection volume was $2.5 \mu \mathrm{L}$. Gradient elution was applied using $0.1 \%$ formic acid in Milli-Q water as solvent A and acetonitrile with $0.1 \%$ formic acid as solvent $B$, according to the following program: $0-0.5 \mathrm{~min}, 7 \% \mathrm{~B} ; 0.5-11.9 \mathrm{~min}, 7-80 \% \mathrm{~B} ; 11.9-12.0 \mathrm{~min}, 80-95 \% \mathrm{~B}$; 12.0-13.0, 95\% B; 13.0-13.1 min., 95-7\% B; 13.1-15 min., 7\% B.

The MS analysis was carried out using the scanning method in the positive and negative ionization mode. The MS settings for the negative ionization mode were as follows: the capillary voltage was $2.8 \mathrm{kV}$; cone voltage was $45 \mathrm{~V}$; source temperature was $140{ }^{\circ} \mathrm{C}$, desolvation temperature was $350{ }^{\circ} \mathrm{C}$, cone gas flow (nitrogen) was $100 \mathrm{~L} \mathrm{~h}^{-1}$, desolvation gas flow was $800 \mathrm{~L} \mathrm{~h}^{-1}$; positive ionization: capillary voltage was $3.1 \mathrm{kV}$, cone voltage was $60 \mathrm{~V}$, other settings were as above. Constituents of the 
extracts were tentatively identified on the basis of their UV spectra and/or MS data. Chlorogenic acid was quantified on the basis of UV chromatograms, using a calibration curve of chlorogenic acid $(y=182.94 x-560.94, R 2=0.9981)$. The contents of other phenolics were expressed as chlorogenic acid equivalents.

Methanol (isocratic and gradient grade), acetonitrile (LC-MS grade), formic acid (LC-MS grade) were from Merck Millipore (Darmstadt, Germany). Standards of oleanolic, ursolic, and chlorogenic acid were from Sigma-Aldrich (Saint Louis, MO, USA).

Extractions and analyzes were performed in triplicate, while the presented results are means-based with standard deviation.

\subsection{Determination of Total Polyphenolic, Phenolic Acid, and Flavonoid Contents}

Samples of lyophilized and powdered biomass were extracted three times with a matched quantity of $80 \%(v / v)$ ethanol for $60 \mathrm{~min}$ at the boiling point temperature of the extractive mixture under reflux. The extracts were evaporated to dryness under a reduced pressure.

The content of phenolics in the ethanol-water extracts $(80 \%, v / v)$ was determined spectrophotometrically using Dóka and Bicanic's (2002) [32] modified method, with the Folin-Ciocalteu reagent. Briefly, $0.05 \mathrm{~mL}$ of the tested extract was mixed with $3.7 \mathrm{~mL}$ of distilled water and $0.25 \mathrm{~mL}$ of the Folin-Ciocalteu reagent. The mixture was shaken vigorously and a $20 \%(w / v)$ sodium dicarbonate solution $(1.0 \mathrm{~mL})$ was added after $1 \mathrm{~min}$. Next, the samples were incubated in the dark for $30 \mathrm{~min}$ at room temperature. The absorbance was measured at $760 \mathrm{~nm}$. The concentration of the total phenolic compounds in the extract was expressed as $\mathrm{mg}$ of the gallic acid equivalent per gram of the dry plant material weight from a calibration curve of gallic acid $(y=9.8399 x+0.0289, R 2=9993)$ in a concentration rate $\left(20-80 \mu \mathrm{g} 10 \mathrm{~mL}^{-1}\right)$. The values are expressed as the mean of 6 replications \pm SD.

The content of phenolic acids in the ethanol-water extracts $(80 \%, v / v)$ was determined by a spectrophotometric method described in Polish Pharmacopeia VI (2002) [33] with Arnov's reagent (10.0 g of sodium molybdate, $10.0 \mathrm{~g}$ of sodium nitrite in $100.0 \mathrm{~mL}$ of water). The sample $(1.0 \mathrm{~mL}) \mathrm{was}$ pipetted into a $10.0 \mathrm{~mL}$ volumetric flask containing $5.0 \mathrm{~mL}$ water; next, $1.0 \mathrm{~mL} \mathrm{HCl}\left(18 \mathrm{~g} \mathrm{~L}^{-1}\right), 1.0 \mathrm{~mL}$ Arnov's reagent and $1.0 \mathrm{~mL} \mathrm{NaOH}\left(40 \mathrm{~g} \mathrm{~L}^{-1}\right)$ were added. The volume was made up to $10.0 \mathrm{~mL}$ with distilled water. The absorbance was measured at $490 \mathrm{~nm}$. The total concentration of the phenolic acid content was expressed as mg of caffeic acid $\left(40-200 \mu \mathrm{g} 10 \mathrm{~mL}^{-1}\right)$ per gram of dry plant material weight from a calibration curve of caffeic acid $(y=11.382 x+0.0746, R 2=0.9834)$ in a concentration rate of 40-300 $\mu \mathrm{g} 10 \mathrm{~mL}^{-1}$. The values are expressed as the mean of 5 replications \pm SD.

The content of flavonoids in the ethanol-water extracts $(80 \%, v / v)$ was determined as described by Meda et al. (2005) [34]. Briefly, equal volumes of $2 \% \mathrm{AlCl}_{3}$ in methanol $(0.7 \mathrm{~mL})$ and the extract $(0.7 \mathrm{~mL})$ were mixed and left for $10 \mathrm{~min}$. The absorbance was measured at $415 \mathrm{~nm}$ using a blank sample of water and methanol without $\mathrm{AlCl}_{3}$. The total concentration of the flavonoid content was expressed as mg of quercetin per gram of the dry plant material weight, from a calibration curve of quercetin $(y=0.046 x-$ $0.0199, \mathrm{R} 2=0.9991)$ in a concentration range $\left(3.125-25 \mu \mathrm{g} \mathrm{mL}^{-1}\right)$. The values are expressed as the mean of 6 replications $\pm \mathrm{SD}$.

\subsection{Determination of Antioxidant Activity DPPH, FRAP, CUPRAC Assays}

The DPPH assay was conducted according to Studzińska-Sroka et al. [35] with modifications. Briefly, $25 \mu \mathrm{L}$ of the dry extracts dissolved in DMSO (Sigma-Aldrich, Saint-Louis, MO, USA) at different concentrations $(0.3125-5 \mathrm{mg} / \mathrm{mL})$ were mixed with a $175 \mu \mathrm{L}$ of DPPH (Sigma-Aldrich, St. Louis, MO, USA) solution (39 mg $50 \mathrm{~mL}^{-1}$ of $\mathrm{MeOH}$; the final assay concentrations were 78.13-625 $\left.\mu \mathrm{g} \mathrm{mL}{ }^{-1}\right)$. The reaction mixture was shaken and incubated in the dark, at room temperature for $30 \mathrm{~min}$. Absorbance was measured at $517 \mathrm{~nm}$ against the blank ( $25 \mu \mathrm{L}$ of DMSO and $175 \mu \mathrm{L} \mathrm{of} \mathrm{MeOH})$. The control contains $25 \mu \mathrm{L}$ of DMSO and $175 \mu \mathrm{L}$ of DPPH solution. The inhibition of the DPPH radical by the sample was calculated according to the following formula: DPPH scavenging activity $(\%)=$ $(\mathrm{A} 0-\mathrm{A} 1) / \mathrm{A} 0 \times 100 \%$, where $\mathrm{A} 0$ is the absorbance of the control and A1 is the absorbance of the 
sample. Analyses were performed in six replicates. Vitamin C was used as a standard $\left(7.5-80 \mu \mathrm{g} \mathrm{mL}{ }^{-1}\right.$; the final assay concentrations were $0.9375-15 \mu \mathrm{g} \mathrm{mL}^{-1}$ ). The results were expressed as the $\mathrm{IC}_{50}$ value corresponds to the concentration of the extract required to inhibit DPPH radical formation by $50 \%$ and was determined from the linear regression analysis.

The FRAP assay was performed according to Tiveron et al. [36] with some modifications. The stock solutions of FRAP reagent included $300 \mathrm{mM}$ acetate buffer ( $\mathrm{pH} 3.6), 10 \mathrm{mM}$ 2,4,6-Tris(2-pyridyl)-s-triazine (TPTZ, Sigma-Aldrich, Saint-Louis, MO, USA) solution in $40 \mathrm{mM}$ $\mathrm{HCl}$, and $20 \mathrm{mM} \mathrm{FeCl} \cdot 6 \mathrm{H}_{2} \mathrm{O}$ (Sigma-Aldrich, Saint-Louis, MO, USA) solution. The working FRAP solution was freshly prepared by mixing $25 \mathrm{~mL}$ of acetate buffer, $2.5 \mathrm{~mL}$ of TPTZ solution, and $2.5 \mathrm{~mL}$ of $\mathrm{FeCl}_{3} \cdot 6 \mathrm{H}_{2} \mathrm{O}$ solution, and then warmed at $37^{\circ} \mathrm{C}$ before usage. Briefly, $25 \mu \mathrm{L}$ of the tested extracts were dissolved in DMSO at different concentrations (0.0125-3.2 mg of extract/mL) was mixed with $175 \mu \mathrm{L}$ of the FRAP solution (the final assay concentrations were 3.125-400 $\mu \mathrm{g} \mathrm{mL}^{-1}$ ), shaken and incubated at $37^{\circ} \mathrm{C}$ for $30 \mathrm{~min}$ in the dark condition. Then the absorbance was read at $593 \mathrm{~nm}$. The analysis was performed in six replicates. Vitamin $C$ was used as a standard $\left(0.0125-0.2 \mathrm{mg} \mathrm{mL}^{-1}\right.$; the final assay concentrations were $0.195-3.125 \mu \mathrm{g} \mathrm{mL}^{-1}$ ). The results were expressed as the $\mathrm{IC}_{0.5}$, which corresponds to the extract concentration required to produce 0.5 O.D. value.

The CUPRAC assay was conducted according to Apak et al. [37] with modifications. The stock solutions of the CUPRAC reagent included equal parts of acetate buffer $(\mathrm{pH}=7.0), 7.5 \mathrm{mM}$ neocuproine (Sigma-Aldrich, St. Louis, MO, USA) solution in $96 \%$ ethanol, and $10 \mathrm{mM} \mathrm{CuCl} 2 \cdot \mathrm{H}_{2} \mathrm{O}$ (Avantor Performance Materials, Gliwice, Poland) solution. Briefly, $50 \mu \mathrm{L}$ of the dry tested extracts dissolved in DMSO at different concentrations $\left(0.0125-1.6 \mathrm{mg} \mathrm{mL}^{-1}\right)$, were mixed with $150 \mu \mathrm{L}$ of CUPRAC solution (the final assay concentrations were 3.125-400 $\mathrm{g} \mathrm{m} \mathrm{mL}^{-1}$ ), shaken and incubated at room temperature for $30 \mathrm{~min}$ in the dark condition. Then the absorbance was read at $450 \mathrm{~nm}$. The analysis was performed in six replicates. Vitamin $C$ was used as a standard $\left(0.0125-0.1 \mathrm{mg} \mathrm{mL}^{-1}\right.$; the final assay concentrations were $\left.3.125-25 \mu \mathrm{g} \mathrm{mL}^{-1}\right)$. The results were expressed as the $\mathrm{IC}_{0.5}$ which corresponds to the extract concentration required to produce 0.5 O.D. value.

\subsection{Biological Activity on Fibroblasts}

The research was carried out on human skin fibroblasts established from male newborns normal foreskin (CRL-2522, ATCC, Manassas, VA, USA). Fibroblasts were cultured in EMEM medium (Corning, New York, NY, USA) supplemented with $100 \mu \mathrm{g} \mathrm{mL}^{-1}$ streptomycin (Cytogen, Sinn, Germany), 100 $\mu \mathrm{g} \mathrm{mL}^{-1}$ penicillin (Cytogen, Sinn, Germany), $2 \mathrm{mmol} \mathrm{L}^{-1}$ L-glutamine (Cytogen, Sinn, Germany), and $10 \%$ fetal bovine serum (FBS, Corning, NY, USA). The cell line was maintained in aseptic conditions at $37{ }^{\circ} \mathrm{C}$ in a humidified, $5 \% \mathrm{CO}_{2}$ incubator and confirmed free of mycoplasma contamination through regular testing (Mycoplasma PCR Test Kit, AppliChem, Darmstadt, Germany). Cells were cultured until $90 \%$ confluence. At this point, they were detached from culture dishes with a trypsin solution (2.5\%, Biowest, Riverside, MO, USA). After 3 min of incubation, the trypsin was removed, complete growth medium was added, and the cell suspension was transferred into sterile Petri dishes. Cells prepared due to this procedure were used for further investigations.

The cell proliferation ratio was evaluated using the xCELLigence RTCA DP system (Roche Diagnostics, Mannheim, Germany; ACEA Biosciences, San Diego, CA, USA). Real-time measurements of cell proliferation were conducted using 16-well plates (F. Hoffmann-La Roche Ltd., Basel, Switzerland; ACEA Biosciences, San Diego, CA 92121 USA). Gold microelectrodes are attached at the bottom of each well for the impedance-based detection of cells biological status, including attachment and cell number. The voltage of about $20 \mathrm{mV}$ applied to the electrodes during the test does not affect the examined cells. The electrical impedance was measured by the integrated software of the xCELLigence RTCA DP system as a cell index (CI). Cells were seeded into the wells at a density of 10,000 cells/well.

Afterward, the cells were treated with callus extracts/fruit extracts/kinetin at different final concentrations: $100,50,25,12.5 \mu \mathrm{g} \mathrm{mL}^{-1}$. The control consisted of cells cultured in a medium without 
addition of the above ligands. Cell proliferation was monitored every $15 \mathrm{~min}$ for $72 \mathrm{~h}$. Cells morphology and viability were evaluated using an Axio Vert.A1 microscope $(10 \times$ and $20 \times$ magnitude, Zeiss, Jena, Germany) by means of propidium iodide/Hoechst33342 double staining after $48 \mathrm{~h}$ of incubation with different ligand concentrations: $100 ; 12.5 \mu \mathrm{g} \mathrm{mL}^{-1}$ and subsequently analyzed with AxioVision software (Zeiss, Jena, Germany). Microscopy analysis was performed on the same selected area on the Petri dish before and after propidium iodide/Hoechst33342 staining.

\subsection{Statistical Analysis}

The collected data from the biotechnological experiments were subjected to a one-way analysis of variance ANOVA, followed by Duncan's post-hoc test. A two-sided P-value of 0.05 was used to declare statistical significance. The Shapiro-Wilk test was used as the normality test of continuous variables. Homogeneity of variance was assessed with the Levene test. A one-way ANOVA followed by Tukey (RIR) post hoc test was used to analyze the relationship between various ligands. Repeated measures of one-way ANOVA with the Tukey-Kramer multiple comparisons test were used to evaluate changes in time for particular ligands. The analysis was made by using Statistica 10 software (StatSoft Inc., Tulsa, OK, USA). Data were presented as mean \pm standard deviation and considered statistically significant at $p<0.05$.

\section{Conclusions}

The stimulation of the proliferation of human skin fibroblasts by C. japonica callus extracts may indicate the prospects for their use in the design of new cosmetic preparations based on plant raw materials.

Author Contributions: M.A.K., A.W. and B.T. collected the plant material, designed, performed and analyzed the data of the biotechnological experiments. A.S. and J.Ż. performed the phytochemical analysis. E.S.-S. conducted the antioxidant activity analysis. M.C. and M.K. performed and analyzed the data of fibroblast studies.

Funding: This research received no external funding.

Conflicts of Interest: The authors declare no conflict of interest.

\section{References}

1. Weber, C. The genus Chaenomeles (Rosaceae). J. Arnold Arbor. 1964, 45, 161-205.

2. Phipps, J.B.; Robertson, K.R.; Smith, P.G.; Rothrer, J.R. A checklist of the subfamily Maloideae (Rosaceae). Can. J. Bot. 1990, 68, 2209-2269. [CrossRef]

3. Rumpunen, K. Chaenomeles: Potential new fruit crop for Northern Europe. In Trends in New Crops and New Uses; Janick, J., Whipkey, A., Eds.; ASHA Press: Alexandria, VA, USA, 2002; pp. 385-392.

4. Rumpunen, K.; Kviklys, D. Combining ability and patterns of inheritance for plant and fruit traits in Japanese quince (Chaenomeles japonica). Euphytica 2003, 132, 139-149. [CrossRef]

5. Hellin, P.; Jordan, M.J.; Vila, R.; Gustafsson, M.; Göransson, E.; Akesson, B.; Gröön, I.; Laencina, J.; Ros, J.M. Processing and products of Japanese quince (Chaenomeles japonica) fruits. In Japanese Quince-Potential Fruit Crop for Northern Europe; Swedish University of Agricultural Sciences: Lomma Municipality, Sweden, 2003; pp. 169-175.

6. Hallmann, E.; Orpel, E.; Rembiałkowska, E. The content of biologically active compounds in some fruits from natural state. Veg. Crop. Res. Bull. 2011, 75, 81-90. [CrossRef]

7. Xu, Y.N.; Kim, J.S.; Kang, S.S.; Son, K.H.; Kim, H.P.; Chang, H.W.; Bae, K. A new acylated triterpene from the roots of Chaenomeles japonica. Chem. Pharm. Bull. 2002, 50, 1124-1125. [CrossRef] [PubMed]

8. Bae, K.H. The Medicinal Plants of Korea; Kyo-Hak Publishing Co. Ltd.: Seoul, South Korea, 2000.

9. European Commission. Available online: http://www.ec.europa.eu (accessed on 14 November 2012).

10. Babaloa, I.; Shode, F.O. Ubiquitous ursolic acid: A potential pentacyclic triterpene natural product-A review. J. Pharmacogn. Phytochem. 2013, 2, 214-222.

11. Liu, J. Pharmacology of oleanolic and ursolic acid. J. Ethnopharm. 1995, 49, 57-68. [CrossRef]

12. Yogeeswari, P.; Sriram, S. Betulinic acid and its derivatives: A review on their biological properties. Curr. Med. Chem. 2005, 12, 657-666. [CrossRef] [PubMed] 
13. Bandhakavi, S.; Kamarapu, P. Production of oleanolic acid by plant cell tissue culture-a review. IPRPC 2016, $4,1-4$.

14. Rasouli, H.; Farzaei, M.H.; Khodarahmi, R. Polyphenols and their benefits: A review. Int. J. Food Prop. 2017, 20,1700-1741. [CrossRef]

15. Działo, M.; Mierzak, J.; Korzun, U.; Preisner, M.; Szopa, J.; Kulma, A. The potential of plant phenolics of prevention and therapy of skin disorders. Int. J. Mol. Sci. 2016, 17, 160. [CrossRef] [PubMed]

16. Smetanska, I. Production of secondary metabolites using plant cell cultures. Adv. Bioch. Engin. Biotechnol. 2008, 111, 187-228. [CrossRef]

17. Karuppusamy, S. A review on trends in production of secondary metabolites from higher plants by in vitro tissue, organ and cell cultures. J. Med. Plant. Res. 2009, 3, 1222-1239.

18. Gunin, G.; Kornilova, N.K.; Petrov, V.V.; Vasilyeva, O.V. Age changes in the number and proliferation of fibroblasts in the human skin. Adv. Gerontol. 2011, 1, 299-303. [CrossRef]

19. Kikowska, M.; Włodarczyk, A.; Rewers, M.; Sliwinska, E.; Studzinska-Sroka, E.; Witkowska-Banaszczak, E.; Stochmal, A.; Żuchowski, J.; Długaszewska, J.; Thiem, B. Polyphenols of micropropagated plants of Chaenomeles japonica and their biological activities. Turk. J. Bot. 2018. (submitted).

20. Suresh, I.; Rattan, S.; Clark, B.F.C. Kinetin delays the onset of ageing characteristics in human fibroblasts. Biochem. Biophys. Res. Commun. 1994, 201, 665-672. [CrossRef]

21. Rattan, S.I.S. N6-Furfuryladenine (kinetin) as a potential anti-aging molecule. J. Anti Aging Med. 2002, 5, 113-116. [CrossRef]

22. Wójciak-Kosior, M.; Paduch, R.; Matysik-Woźniak, A.; Niedziela, P.; Donica, H. The effect of ursolic and oleanolic acids on human skin fibroblast cells. Folia Histoch. Cytobiol. 2011, 49, 664-669. [CrossRef]

23. Both, D.M.; Goodtzova, K.; Yarosh, D.B.; Brown, D.A. Liposome-encapsulated ursolic acid increases ceramides and collagen in human skin cells. Arch. Dermatol. Res. 2002, 293, 569-575. [CrossRef] [PubMed]

24. Rhourri-Frih, B.; Renimel, I.; Chaimbault, P.; Andre, P.; Herbette, G.; Lafosse, M. Pentacyclic triterpenes from Manilkara bidentate resin. Isolation, identification and biological properties. Fitoterapia 2013, 88, 101-108. [CrossRef] [PubMed]

25. Wardecki, T.; Werner, P.; Thomas, M.; Templin, M.F.; Schmidt, G.; Brander, J.M.; Merfort, I. Influence of birch bark triterpenes on keratinocytes and fibroblasts from diabetic and nondiabetic donors. J. Nat. Prod. 2016, 79, 1112-1123. [CrossRef] [PubMed]

26. Lee, J.H.; Kim, H.-L.; Lee, M.H.; You, K.E.; Kwon, B.J.; Seo, H.J.; Park, Ch. Asiaticoside enhances normal human skin cell migration, attachment and growth in vitro wound healing model. Phytomedicine: Int. J. Phytother. Phytopharmacol. 2012, 19, 1223-1227. [CrossRef] [PubMed]

27. Singh, D.; Singh, D.; Choi, S.M.; Zo, S.M.; Painuli, R.M.; Kwon, S.W.; Han, S.S. Effect of extracts of Terminalia chebula in proliferation of keratinocytes and fibroblasts cells: An alternative approach for wound healing. Evid. Based. Complement Alternat. Med. 2014, 1, 1-13. [CrossRef] [PubMed]

28. Sowa, I.; Paduch, R.; Strzemski, M.; Zielińska, S.; Rydzik-Strzemska, E.; Sawicki, J.; Kocjan, R.; Polkowski, J.; Matkowski, A.; Latalski, M.; Wójciak-Konor, M. Proliferative and antioxidant activity of Symphytum officinale root extract. Nat. Prod. Res. 2017, 32, 605-609. [CrossRef] [PubMed]

29. Ramos-Jerz, M.; Villanueva, S.; Jerz, G.; Winterhalter, P.; Deters, A.M. Persea americana Mill. seed: Fractionation, characterization, and effects on human keratinocytes and fibroblasts. Evid. Based Complement. Alternat. Med. 2013, 2013, 391247. [CrossRef] [PubMed]

30. Badgas, D.; Gul, N.Y.; Topal, A.; Tas, S.; Ozyigit, M.O.; Cinkilic, N.; Gul, Z.; Etoz, B.C.; Ziyanok, S.; Inan, S. Pharmacologic overview of systemic chlorogenic acid therapy on experimental wound healing. Naunyn-Schmiedeberg's Arch. Pharmacol. 2014, 387, 1101-1116. [CrossRef]

31. Murashige, T.; Skoog, F. A revised medium for rapid growth and bioassays with tobacco cultures. Physiol. Plant. 1962, 15, 473-497. [CrossRef]

32. Dóka, O.; Bicanic, D. Determination of total polyphenolic content in red wines by means of the combined He-Ne laser optothermal window and Folin-Ciocalteu colorimetry assay. Anal. Chem. 2002, 74, 2157-2161. [CrossRef] [PubMed]

33. Polish Pharmacopeia VI. Polish Pharmaceutical Society: Warsaw, Polish, 2002. Available online: http:/ / www. urpl.gov.pl/en/polish-pharmacopoeia (accessed on 16 November 2018). 
34. Meda, A.; Lamien, Ch. E.; Romito, M.; Millogo, J.; Nacoulma, O.G. Determination of the total phenolic, flavonoid and proline contents in Burkina Fasan honey, as well as their radical scavenging activity. Food Chem. 2005, 91, 571-577. [CrossRef]

35. Studzińska-Sroka, E.; Piotrowska, H.; Kucińska, M.; Murias, M.; Bylka, W. Cytotoxic activity of physodic acid and acetone extract from Hypogymnia physodes against breast cancer cell lines. Pharm Biol. 2016, 54, 2480-2485. [CrossRef] [PubMed]

36. Tiveron, A.P.; Melo, P.S.; Bergamaschi, K.B.; Vieira, T.M.; Regitano-d'Arce, M.A.; Alencar, S.M. Antioxidant activity of Brazilian vegetables and its relations with phenolic composition. Int. J. Mol. Sci. 2012, 13, 8943-8957. [CrossRef] [PubMed]

37. Apak, R.; Güçlü, K.; Özyürek, M.; Çelik, S.E. Mechanism of antioxidant capacity assays and the CUPRAC (cupric ion reducing antioxidant capacity) assay. Microchim. Acta 2008, 160, 413-419. [CrossRef]

Sample Availability: Samples of the callus lines are available from the authors.

(C) 2018 by the authors. Licensee MDPI, Basel, Switzerland. This article is an open access article distributed under the terms and conditions of the Creative Commons Attribution (CC BY) license (http://creativecommons.org/licenses/by/4.0/). 